investigations involves analysis of the shift in cellular metabolism that the bladder epithelia cells (RT4) undergo to sustain the hostile environment generated by $\mathrm{B}[\mathrm{a}] \mathrm{P}$-induced toxicity.

Methods We applied the two-dimensional blue native SDSPAGE (2D BN/SDS-PAGE) technique to elucidate the network of protein-protein interactions that regulate cellular metabolism. In order to analyse the effects of $\mathrm{B}[\mathrm{a}] \mathrm{P}$-induced protein alterations at the metabolite level, untargeted metabolomic profiling of $\mathrm{B}[\mathrm{a}] \mathrm{P}$-exposed cells was carried out by using gas chromatographic mass spectrometric analysis (GC-MS).

Results It appeared that $\mathrm{B}[\mathrm{a}] \mathrm{P}$ exposure led to a repression of enzymes (fructose-bisphosphate aldolase A, glucose-6-phosphate isomerase, lactate dehydrogenase) involved in glycolysis, and an up-regulation of proteins (glucose-6-phosphate 1-dehydrogenase, 6-phosphogluconolactonase) catalysing the pentose phosphate pathway and one carbon metabolism (10-formyltetrahydrofolate dehydrogenase, bifunctional purine biosynthesis protein). Untargeted metabolomics analysis revealed, lower concentration of glycolytic metabolites, as compared to glutamine, xylulose and fatty acids. The analysis of the glutathione and nucleotide content of the cells revealed a significant increase of these cofactors. Concomitantly, we did not observe any detectable increase in the production of ROS.

Discussion The study provides new insights into a $\mathrm{B}[\mathrm{a}] \mathrm{P}-$ induced shift in cellular metabolism towards processes involved in NADPH generation. B[a]P exposure causes oxidative DNA damage and hence cellular perturbations. To overcome these effects, the cells undergo a metabolic flux change from glycolysis to the pentose phosphate pathway. This shift leads to the generation of the redox cofactor NADPH that is essential for the activity of many antioxidant enzymes and intermediates necessary for the de novo generation of nucleotides (purine and pyrimidine) and for the normal functioning of the cells. The study provides preliminary indication of changes in cellular metabolism upon $\mathrm{B}[\mathrm{a}] \mathrm{P}$ exposure.

\section{HEALTH EFFECTS FOLLOWING OCCUPATIONAL EXPOSURE TO PAVING ASPHALT FUMES}

${ }^{1} \mathrm{M}$ Neghab, ${ }^{2} \mathrm{~F}$ Zare Derisi, ${ }^{3} \mathrm{~J}$ Hassanzadeh. 'Department of Occupational Health and Research Centre for Health Sciences, Shiraz University of Medical Sciences, Shiraz, Iran; ${ }^{2}$ Student Research Committee, School of Health, Shiraz University of Medical Sciences, Shiraz, Iran; ${ }^{3}$ Department of Clinical Epidemiology, School of Health, Shiraz University of Medical Sciences, Shiraz, Iran

\subsection{6/oemed-2018-ICOHabstracts.1177}

Introduction Controversy exists as to the potential of asphalt fumes to induce health effects including respiratory, hepatotoxic, nephrotoxic, or hematotoxic responses. The main purpose of this study was to ascertain whether occupational exposure to asphalt fumes, under normal working conditions, is associated with any respiratory, hepatotoxic, nephrotoxic, or hematotoxic response.

Methods In this cross-sectional study in which 210 subjects (80 exposed and 130 reference subjects) were investigated. Using standard methods, atmospheric concentrations of total particulate and benzene-soluble fractions of asphalt fumes, as well as total particulate were measured. Additionally, urine and blood samples were taken from subjects for complete blood count, white blood cell differential test, urinalysis, and routine biochemical tests of kidney and liver function. For The prevalence of respiratory symptoms among subjects was investigated by a standard questionnaire. Additionally, the parameters of pulmonary function were measured both, prior to exposure and at the end of work-shift.

Results Both groups were similar as far as their demographic variables and smoking habits were concerned. The association between exposure to asphalt fumes and changes in most liver and kidney function tests and complete blood count parameters was statistically significant. Mean values of FEV1, both prior to the exposure (89.58\% [SD 18.69\%] predicted value) and at the end of shift (85.38\% [SD 19.4\%]), were significantly $(\mathrm{p}<0.05)$ smaller than those of the comparison subjects (93.88\% [SD 13.93\%]). Similarly, pre-shift (87.05 [SD 8.57]) and postexposure (89.95 [SD 6.85]) FEV1/FVC ratio were both significantly $(\mathrm{p}<0.01)$ lower than those of the unexposed employees (107.56 [SD 9.64]). The pattern of changes in parameters of lung function in asphalt workers was consistent with that of chronic obstructive lung disease.

Conclusion This study showed that exposure to sub-threshold limit value levels of total particulate and benzene-soluble fractions is associated with early liver and kidney dysfunction as well as haematological disorders. Also, significant decrements in the parameters of pulmonary function as well as, a significant increase in the prevalence of respiratory symptoms in asphalt paving workers compared to their unexposed counterparts provided evidence in favour of a significant association between exposure to asphalt fumes and lung function impairments.

\section{USE OF URINARY BIOMARKERS AND BIOASSAYS TO EVALUATE CHEMICAL EXPOSURE AND ACTIVATION OF CANCER PATHWAYS IN FIREFIGHTERS}

${ }^{1} \mathrm{C}$ Hoppe-Jones, 'S Beitel, ' 'JL Burgess*, 'S Snyder, 'L Flahr, 'S Griffin, 'S Littau, ${ }^{2} \mathrm{KS}$ Jeong, '1 Zhou, ${ }^{3} \mathrm{~J}$ Gulotta, ${ }^{3} \mathrm{P}$ Moore. 'University of Arizona, Tucson, USA; ${ }^{2}$ Dongguk University, Seoul, South Korea; ${ }^{3}$ Tucson Fire Department, Tucson, USA

\subsection{6/oemed-2018-ICOHabstracts.1178}

Introduction Cancer is a leading cause of fire service morbidity and mortality. Measurement of urinary polycyclic aromatic hydrocarbons (PAHs), a group which includes known carcinogens, provides a means of evaluating absorption from all exposure routes. Activation of the aryl hydrocarbon receptor (AhR) and p53 pathways is associated with cancer, and their evaluation through in vitro urinary bioassays provides measures of toxicity of the chemical mixtures to which firefighters are exposed.

Methods Urine was collected at baseline and two hours after responding to fires in 80 Tucson firefighters. Urine contaminants were de-conjugated using $\beta$-Glucuronidase and extracted using Focus Solid Phase Extraction (SPE) cartridges. Quantification of hydroxylated PAH (PAH-OH) target analytes was conducted with GC-MS/MS. In addition, the urinary extracts were evaluated using AhR and p53 in vitro bioassays.

Results Compared to baseline, structural firefighting was associated with an increase in urinary $\mathrm{PAH}-\mathrm{OH}$ concentrations. Increased concentrations were also found in training fires when self-contained breathing apparatus (SCBA) were used assiduously, suggesting a primary route of dermal exposure in that setting. Contrary to expectations, engineers (vehicle drivers) also demonstrated increased urinary $\mathrm{PAH}-\mathrm{OH}$ concentrations, which was felt to be due to inhalation exposure as they generally did not wear SCBA. AhR and p53 activation occurred in general with higher concentrations of $\mathrm{PAH}-\mathrm{OH}$ 
in the urine, but extent of activation was not highly correlated with any single urinary $\mathrm{PAH}-\mathrm{OH}$ marker.

Conclusion Among firefighters, urinary $\mathrm{PAH}-\mathrm{OH}$ concentrations increase in both entry teams and engineers. The route and extent of dermal and inhalation exposure vary with the specific job task at the fireground. AhR and p53 in vitro bioassays demonstrate activation of cancer pathways following occupational exposure in firefighters.

\section{HUMAN BIO-MONITORING OF EPOXY RESINS AND HARDENERS IN THE PRODUCTION OF ROTOR: BLADES}

${ }^{1} \mathrm{~T}$ Schettgen, ${ }^{1} \mathrm{M}$ Krichels, ${ }^{2} \mathrm{~B}$ Rossbach, ${ }^{1} \mathrm{~T}$ Kraus. IInstitute of Occupational and Social Medicine, RWTH Aachen University; ${ }^{2}$ Institute of Occupational, Social and Environmental Medicine, University Medical Centre of the Johannes Gutenberg-University, Mainz

\subsection{6/oemed-2018-ICOHabstracts.1179}

Introduction In a small company producing rotor blades for aviation from carbon composites, epoxy resins based on Novolac and isophorone diamine as hardener are used. Both compounds can be absorbed via skin contact and were shown to be strong skin sensitizers. As a part of risk assessment, the industrial physician prompted a biological monitoring to determine the internal exposure of the workers.

Methods 6 workers were identified with potential contact to the hardener and resin. We have collected pre- and post-shift urine samples at the beginning and mid of the work week and analysed them for the concentration of isophoronediamine and bisphenol-f-diglycidylethermetabolites as biomarker for the hardener and Novolac via specific mass spectrometric methods.

Results We detected isophoronediamine in almost all urine samples with post-shift-values significantly higher than preshift. Median urinary excretion of isophoronediamine over the workweek was $195 \mu \mathrm{g} / \mathrm{g}$ crea. (Monday pre-shift), $709 \mu \mathrm{g} / \mathrm{g}$ crea. (Monday post-shift), $573 \mu \mathrm{g} / \mathrm{g}$ crea. (Wednesday pre-shift) and $1319 \mu \mathrm{g} / \mathrm{g}$ crea. (Wednesday post-shift). Results for urinary bisphenol-f-diglycidylether-metabolites were several orders of magnitude lower and near the limit of detection $(0.5 \mu \mathrm{g} / \mathrm{L})$.

Conclusion We found considerable internal exposures to isophoronediamine in workers producing carbon composite rotor blades. Our results indicate a cumulating internal exposure over the work-week. One of the workers showed clinical symptoms of allergic contact dermatitis in the skin examination. Use of inappropriate gloves was determined to be the cause for these high exposures. Biological monitoring should be part of risk assessment of workers handling epoxy resins.

\section{EXPOSURE FROM GUN SMOKE ACTIVATES SEVERAL SYSTEMIC INFLAMMATORY PATHWAYS}

\footnotetext{
${ }^{1,2} \mathrm{~J}$ Kongerud, ${ }^{3,4} \mathrm{AK}$ Borander, ${ }^{5} \varnothing$ Voie, ${ }^{6} \mathrm{R}$ Øvstebø, ${ }^{5} \mathrm{~K}$ Longva, ${ }^{7} \mathrm{NE}$ Alexis, ${ }^{1,8} \mathrm{~T}$ Ueland, 1,2LIB Sikkeland. 'Institute of Clinical Medicine, Faculty of Medicine, University of Oslo, Olso, Norway; ${ }^{2}$ Department of Respiratory Medicine, Oslo University Hospital Rikshospitalet, Oslo, Norway; ${ }^{3}$ Department of Environmental and Occupational Medicine, Oslo University Hospital, Oslo, Norway; ${ }^{4}$ The Occupational Health Service in the Norwegian Armed Forces, Sessvollmoen, Norway; ${ }^{5}$ Norwegian Defence Research Establishment, Division Protection, Kjeller, Norway; ${ }^{6}$ The Blood Cell Research Group, Dept. of Med. Biochemistry, Oslo Univ. Hosp. Ullevål, Oslo, Norway; ${ }^{7}$ Center for Environmental Medicine, Asthma and Lung Biology, UNC Chapel Hill, North Carolina, USA; ${ }^{8}$ Research Institute of Internal Medicine, Oslo University Hospital. Rikshospitalet, Oslo, Norway
}

10.1136/oemed-2018-ICOHabstracts. 1180
Introduction Norwegian Armed Forces reported episodes of acute respiratory symptoms after exposure to fumes from firing small arms weapon HK416 (Heckler and Koch) using unleaded ammunition. These fumes contain a mixture of gases and solid particles, that may be capable of inducing inflammatory immune responses. The aim of the present study was to find out if exposure to fumes from small arms could induce systemic and airway inflammation, and whether there were any differences between the ammunition types (leaded, and two types of unleaded).

Methods Fifty-five healthy men (age 19-62) were recruited and randomised to three groups using HK416 and one of the three types of ammunition. Spirometry and collection of blood and sputum samples were performed 2-4 days before shooting, and 1.5 hour (spirometry), 24 hour (blood and spirometry) and 48 hour (sputum) after shooting under standardised conditions. Exposure was monitored.

Results All subjects had a significant increase in median sputum and blood neutrophils (sputum: $46 \%$ to $73 \%, \mathrm{p}<0.001$; blood: $2.9 \times 10^{6} / \mathrm{mL}$ to $\left.7.1 \times 10^{6} / \mathrm{mL}, \mathrm{p}<0.001\right)$. CRP was significantly elevated from $1.3 \mathrm{mg} / \mathrm{L}$ to $18.5 \mathrm{mg} / \mathrm{L}(\mathrm{p}<0.001)$ along with other markers of systemic inflammation (PTX3, YKL-40, SpD, CC16, CXCL16, vWF, MPO, CD25, CD14). CRP and number of neutrophils in blood had a larger increase with unleaded as compared to leaded ammunition. For the whole group, mean $\mathrm{FEV}_{1}$ and FVC decreased $290 \mathrm{~mL}$ $(\mathrm{p}<0.001)$ and $130 \mathrm{~mL}(\mathrm{p}<0.001)$, respectively.

Discussion All subjects displayed elevated airway and in particular systemic inflammation following the use of small arms. The changes in systemic markers were enhanced acute stress response (CRP, PTX3), immune cell upregulation (sCD25, sCD14) and increased vascular inflammation (MPO, vWF, CXL16, YKL40). Increased airway inflammation was present at 48 hour post exposure and was accompanied by reduced spirometry that appeared $<1.5$ hour and lasted $>24$ hour after exposure. These results suggest that soldiers may be at increased risk to inflammation-based disorders when repeatedly using small arms.

\section{COMBINATION OF CELLULAR ASSAYS WITH METABOLOMICS REVEALED MECHANISTIC INSIGHTS ON DOSE-RESPONSE RELATIONSHIP OF 3- NITROBENZANTHRONE IN HUMAN UROTHELIAL CANCER CELLS}

Simone Schmitz-Spanke*, Nisha Verma, Anna Zerries, and Mario Pink. Institute and Outpatient Clinic of Occupational, Social and Environmental Medicine, University of Erlangen-Nuremberg, Schillerstr, 25/29, 91054 Erlangen, Germany

\subsection{6/oemed-2018-ICOHabstracts.1181}

Introduction A product of incomplete combustion of diesel fuel, 3-nitrobenzanthrone (3-NBA), has been classified as a cancer-causing substance. It gained attention as a potential urinary bladder carcinogen due to the presence of its metabolite in urine and formation of DNA adducts.

The aim of this study was to characterise the dose-response relationship starting from environmentally relevant to high concentrations by utilising toxicological and metabolomic approaches to determine the toxic potential of 3-NBA in bladder cells.

Method Cells of RT4 cells were exposed against $0.3 \mathrm{nM}$ to $80 \mu \mathrm{M} 3-\mathrm{NBA}$ for 24 hour. Both activity of enzymes involved in the metabolism of $3-\mathrm{NBA}$ as well as cytotoxicity were 